\title{
INFLUÊNCIA DO GRAU ALCOÓLICO E DA ACIDEZ DO DESTILADO SOBRE O TEOR DE COBRE NA AGUARDENTE DE CANA
}

\author{
YOLANDA BOZA * \\ JORGE HORII **
}

\begin{abstract}
O uso de cobre na confecção de destiladores e acessórios para a indústria de bebidas destiladas favorece a qualidade sensorial da bebida. $O$ presente trabalho teve por escopo correlacionar o teor de cobre na aguardente de cana com o grau alcoólico e a acidez do destilado. Constatou-se que os teores de cobre durante a destilação acompanham os teores de acidez do destilado, encontrando-se ambos em maior concentração na fração cauda. Cortando-se a destilação do produto com alto grau alcoólico os teores de acidez e de cobre são reduzidos.
\end{abstract}

\section{INTRODUÇÃO}

A presença de cobre nas bebidas destiladas tem sido um dos problemas intrínsecos à sua produção, pois desde o início da elaboração de bebidas fermento-destiladas, o cobre é o material mais extensivamente utilizado nas construções de alambiques. Tal fato se deve às vantagens que apresenta, ou seja, resistência à corrosão e boa condução de calor, além de reagir com alguns componentes do vinho e atuar como catalisador em reações altamente favoráveis às características sensoriais da bebida (9).

Nas aguardentes brasileiras o cobre aparece com freqüência, porém a legislação atual (4) permite o limite máximo de $5 \mathrm{mg} / \mathrm{L}$, o que pode ser facilmente garantido com higienização correta e constante dos equipamentos de destilação. Entretanto, a presença de cobre e a falta de padrões de qualidade têm sido os principais obstáculos à sua exportação, pois a maioria dos países importadores não aceita bebidas contaminadas por cobre $(5,6)$.

* Química, Pós-Graduada em Ciência e Tecnologia de Alimentos, Escola Superior de Agricultura "Luiz de Queiroz" (ESALQ), Universidade de São Paulo (USP), Piracicaba, SP (e-mail: yboza@bol.com.br).

** Doutor, Professor, ESALQ/USP, Piracicaba, SP, Brasil. (e-mail: jhorii@carpa.ciagri.usp.br). 
O cobre é essencial ao metabolismo em níveis de traço, sendo que o Food Nutritional Board (FBN) estabeleceu o Recommended Dietary Alowance (RDA) para o cobre entre 1,5 a $3,0 \mathrm{mg} / \mathrm{dia}$ para adultos (18). Alguns estudos sobre a atuação do cobre no organismo revelam sua associação com óxido-redutases dos tecidos e também com a absorção de ferro da dieta para biossíntese de hemoglobina. Porém o excesso deste metal causa lesões nos vasos capilares, no fígado e nos rins além da chamada doença de Wilson, caracterizada pela precipitação deste metal na córnea, resultante do acúmulo de cobre nos tecidos (21).

A presença de cobre nas aguardentes é uma preocupação antiga dos pesquisadores brasileiros. PEDUTI (17) constatou a presença de cobre em grande número de aguardentes, especialmente naquelas cujas características organolépticas indicavam boa origem. Salientou ainda a toxidez do cobre à saúde pública por se apresentar na forma assimilável.

LIMA NETO \& FRANCO (10) e BEZERRA (2) avaliando amostras de aguardentes de cana de diversas regiões produtoras do País, compreendendo produtos comerciais e artesanais, verificaram teores médios de cobre de 3,9 a $4,2 \mathrm{mg} / \mathrm{L}$, inferiores portanto ao limite estabelecido por lei. Contudo os mesmos autores observaram teores de cobre de até $14 \mathrm{mg} / \mathrm{L}$ e que $25 \%$ das amostras analisadas apresentaram teores superiores ao estabelecidos pela legislação.

$\mathrm{Na}$ destilação do vinho, o ataque dos vapores ácidos ao cobre metálico gera o azinhavre [Cu O Cu $(\mathrm{OH})_{2}$ ], que é dissolvido durante a operação de destilação, contaminando o produto final. TANNER (23) recomenda, para minimizar a contaminação por cobre, que os equipamentos de destilação tenham as partes ascendentes construídas em cobre e as partes descendentes (seção de resfriamento) em aço inoxidável. Desta forma, previne-se a formação de acetatos de cobre, os quais durante a estocagem da bebida podem reagir com outros ácidos, resultando em produtos de coloração verde.

As vantagens e desvantagens do uso de cobre na construção de aparelhos destilatórios motivaram vários estudos. LIMA (11) verificou que o material de construção de aparelhos destilatórios não influi na composição do coeficiente de congêneres das aguardentes e sim na técnica de destilação utilizada. Por outro lado, FARIA (6) mediante estudo comparativo de aguardentes destiladas, na presença e na ausência de cobre, verificou que a sua presença no alambique causa redução na acidez e nos teores de aldeídos e de compostos sulfurados. Sugeriu a participação dos compostos sulfurados no defeito organoléptico observado nas aguardentes destiladas em ausência de cobre.

Os componentes sulfurados presentes no fermentado compreendem substâncias que contém enxofre na forma de sulfato (SO4)2- e de 
dissulfeto (-S-S-), usualmente não voláteis e em maior proporção e menor proporção de gás sulfídrico (H2S) e de mercaptanas $(12,24)$. Durante a destilação do fermentado o gás sulfídrico é eliminado com facilidade, porém algumas mercaptanas são líquidos voláteis que, quando transferidos para o destilado, mesmo em níveis de partes por bilhão (ppb) conferem-lhe aroma desagradável. A presença de cobre no domo do alambique é particularmente favorável, uma vez que o íon cúprico (do azinhavre) catalisa a oxidação do gás sulfídrico e das mercaptanas a sulfetos de cobre e dissulfetos, compostos de baixa solubilidade, reduzindo assim a concentração de compostos sulfurados nos destilados $(12,14)$.

Os sais de cobre durante a destilação mudam o perfil do destilado pois, segundo OSSA \& SERRANO (16), alteram a composição de equilíbrio líquido-vapor, obtendo-se maior separação entre os componentes e aumento pelo efeito catalítico na concentração de acetato de etila, com correspondente redução na concentração de acetaldeído. O cobre também reage com ácidos de odor desagradável, tais como o ácido butírico, o caprílico e o láurico, formando compostos organo-cúpricos, insolúveis no meio de destilação (1).

A literatura apresenta vários levantamentos sobre teores de cobre em aguardentes, porém poucos são os trabalhos que abordam possíveis soluções tecnológicas para reduzir os níveis de contaminação no produto. Levando-se em conta estas considerações, a presente pesquisa teve como objetivo correlacionar o teor de cobre com o grau alcoólico e a acidez do destilado.

\section{MATERIAL E MÉTODOS}

\subsection{MATERIAL}

O vinho foi obtido mediante inoculação de Saccharomyces cerevisiae (fermento biológico prensado comercial - Fleischmann), em concentração celular da ordem de $3 \mathrm{~g} / \mathrm{L}$, em caldo de cana de açúcar diluído com água potável até teor de sólidos solúveis ( ${ }^{\circ}$ Brix) em torno de 16 e suplementado com sulfato de amônio $(0,1 \mathrm{~g} / \mathrm{L})$ e fosfato de potássio $(0,1 \mathrm{~g} / \mathrm{L})$. A fermentação foi conduzida sob as seguintes condições: $30-32{ }^{\circ} \mathrm{C}$, com agitação de $380 \mathrm{rpm}$ em fermentador de aço inox com capacidade para $15 \mathrm{~L}$. O vinho foi decantado e o sobrenadante destilado em alambique, tipo Besnard-Estève modificado, de carga intermitente com capacidade de $12 \mathrm{~L}$, com 5 pratos perfurados concentradores e condensador superiormente acoplado, sendo que os pratos e o condensador (tipo resfriadeira) eram de cobre.

O destilado foi recolhido em frações sucessivas de $100 \mathrm{~mL}$ ou múltiplo, sendo determinado nestas o grau alcoólico e os teores de acidez e de 
cobre. O experimento foi repetido três vezes e as análises efetuadas em triplicata.

\subsection{MÉTODOS}

\subsubsection{Determinação da concentração celular}

Utilizou-se o método direto, segundo SINGH et al. (22). Alíquotas de $20 \mathrm{~mL}$ do caldo de cana inoculado foram centrifugadas a 1600 x g a $5^{\circ} \mathrm{C}$ por 30 minutos. O "pellet" (células) foi ressuspendido em água destilada e centrifugado novamente. O "pellet" final foi transferido para placa, previamente seca e tarada, e o peso seco determinado após a secagem em estufa a $105{ }^{\circ} \mathrm{C}$, resfriamento em dessecador e pesagem até peso constante. A determinação foi feita em triplicata e a concentração celular expressa em $\mathrm{g} / \mathrm{L}$.

\subsubsection{Determinação da concentração alcoólica (\%v)}

A concentração alcoólica foi obtida pela conversão, em tabela apropriada, dos valores de densidade determinados a $20^{\circ} \mathrm{C}$ em densímetro AntonPaar, modelo DMA 45.

\subsubsection{Determinação da acidez total}

A acidez total foi efetuada segundo as normas analíticas do Instituto Adolfo Lutz (8).

\subsubsection{Determinação de cobre}

\subsubsection{Preparo das amostras}

As frações de destilado tiveram o teor alcoólico corrigido para, aproximadamente, $40 \%$ em volume a $20{ }^{\circ} \mathrm{C}$ pela adição de álcool etílico ou água desmineralizada, segundo RODELLA (19).

A solução estoque foi preparada a partir de sulfato de cobre pentahidratado, álcool etílico e água, obtendo-se solução com concentração de cobre de $1000 \mathrm{mg} \mathrm{L}^{-1}$ e teor alcoólico de $40 \%$ em volume a $20{ }^{\circ} \mathrm{C}$. Empregaram-se reagentes de grau analítico. A partir da solução estoque foram preparadas as soluções-trabalho pela diluição com solução hidroalcoólica a $40 \%$ em volume a $20^{\circ} \mathrm{C}$.

\subsubsection{Análise de cobre}

As determinações de cobre foram efetuadas em espectrômetro de absorção atômica, marca Intralab-Gemini, modelo AA12/1475, com chama 
de ar - acetileno e lâmpada de cátodo oco de cobre, a $324,8 \mathrm{~nm}$, com abertura de fenda $0,7 \mathrm{~nm}$ e intensidade de corrente $4 \mathrm{~mA}$.

\subsubsection{Análise estatística}

A análise dos dados foi efetuada pelo sistema SAS (20) e o estudo de correlações entre os analitos das frações foi realizado pelo procedimento CORR.

\section{RESULTADOS E DISCUSSÃO}

Os resultados das análises do grau alcoólico e dos teores de acidez e de cobre das frações estão apresentados na Tabela 1. Observou-se que há correlação entre os teores de ácidos e de cobre, sendo que as frações cabeça (início) e cauda (final) da destilação, aqui caracterizadas pelos pontos de inflexões da curva de acidez (Figura 1), apresentaram maior acidez total e maior teor de cobre.

\section{TABELA 1 - RESULTADO DAS DETERMINAÇÕES DE GRAU ALCOÓLICO, TEOR DE ACIDEZ E DE COBRE DAS FRAÇÕES SEQÜENCIAIS E DO DESTILADO}

\begin{tabular}{|c|c|c|c|c|c|c|}
\hline \multirow{2}{*}{$\begin{array}{c}\begin{array}{c}\text { Volume } \\
\mathrm{mL}\end{array} \\
\text { TOTAL* }\end{array}$} & \multicolumn{2}{|c|}{$\begin{array}{c}\text { Grau Alcoólico } \\
\mathrm{mL} / 100 \mathrm{~mL}\end{array}$} & \multicolumn{2}{|c|}{$\begin{array}{c}\text { ACIDEZ } \\
\mathrm{mg} \mathrm{HAc} / 100 \mathrm{~mL} \\
\end{array}$} & \multicolumn{2}{|c|}{$\begin{array}{c}\mathrm{COBRE} \\
\mathrm{mg} / \mathrm{L}\end{array}$} \\
\hline & FRAÇÃO & TOTAL* & FRAÇÃO & TOTAL* & FRAÇÃO & TOTAL* \\
\hline 100,00 & 86,38 & - & 14,95 & - & 9,41 & - \\
\hline 200,00 & 87,07 & 86,72 & 8,60 & 11,77 & 14,28 & 11,80 \\
\hline 300,00 & 86,84 & 86,76 & 6,82 & 10,12 & 11,35 & 11,70 \\
\hline 400,00 & 86,58 & 86,72 & 6,23 & 9,15 & 7,76 & 10,70 \\
\hline 500,00 & 86,25 & 86,62 & 5,64 & 8,45 & 4,48 & 9,50 \\
\hline 600,00 & 85,83 & 86,49 & 4,15 & 7,73 & 6,98 & 9,00 \\
\hline 700,00 & 84,83 & 86,25 & 5,76 & 7,45 & 3,39 & 8,20 \\
\hline 800,00 & 84,02 & 86,00 & 6,05 & 7,27 & 1,10 & 7,30 \\
\hline 1000,00 & 81,38 & 85,10 & 6,94 & 7,21 & 2,58 & 6,40 \\
\hline 1214,00 & 60,69 & 80,76 & 14,95 & 8,57 & 12,73 & 7,50 \\
\hline 1401,5 & 26,42 & 73,49 & 21,96 & 10,36 & 25,32 & 9,90 \\
\hline 1501,5 & 18,19 & 69,81 & 24,03 & 11,27 & 29,64 & 11,20 \\
\hline 1601,5 & 13,38 & 66,28 & 25,04 & 12,13 & 31,96 & 12,50 \\
\hline 1701,5 & 9,72 & 62,96 & 21,07 & 12,66 & 37,12 & 13,90 \\
\hline 1801,5 & 8,08 & 59,91 & 22,25 & 13,19 & 46,75 & 15,80 \\
\hline 1914,0 & 3,25 & 56,58 & 22,25 & 13,72 & 44,00 & 17,40 \\
\hline 2016,5 & 1,58 & 53,79 & 22,25 & 14,16 & 45,72 & 18,70 \\
\hline 2116,5 & 0,70 & 51,29 & 22,96 & 14,57 & 46,32 & 20,20 \\
\hline 2232,5 & 0,29 & 48,64 & 24,03 & 15,06 & 44,76 & 21,40 \\
\hline 2335,0 & 0,16 & 46,51 & 20,89 & 15,32 & 48,12 & 22,60 \\
\hline
\end{tabular}

* Composição do destilado (concentração total obtida por cálculo a partir dos teores de analitos encontrados nas frações seqüenciais). 
Resultados semelhantes foram obtidos por FURTADO (7), segundo o qual os valores de acidez total e volátil mostram-se maiores na fração cauda, enquanto a acidez fixa foi maior na fração cabeça. MOUTOUNET et al. (13) relataram que os destilados obtidos em coluna contínua apresentaram maior proporção de produtos de cauda (alta polaridade e ponto de ebulição), sendo mais ricos em ácidos (acidez total e volátil). Também apresentaram menores valores de pH e maior concentração em sais de cobre, enquanto os destilados obtidos em alambiques mostraram-se mais ricos em produtos de cabeça e apresentaram menores teores de acidez e de sais de cobre.

As Figuras 1 e 2 evidenciam que no transcorrer da destilação ocorre variação da acidez no destilado e concomitantemente na concentração de sais de cobre do destilado. A variação da acidez durante a destilação foi anteriormente verificada por LÉAUTÉ (9), segundo o qual também há alteração na composição dos ácidos nas frações do destilado no transcorrer da destilação. Na primeira destilação do fermentado em alambique, os ácidos graxos compostos com relativamente alto ponto de ebulição e inteiramente ou parcialmente solúveis em etanol terminam de destilar no meio da fração coração, enquanto o ácido acético, cujo ponto de ebulição é maior que o da água, além de ser solúvel em água inicia a destilação no meio da fração coração.

FIGURA 1 - VARIAÇÃO DA ACIDEZ TOTAL NAS FRAÇÕES DO DESTILADO

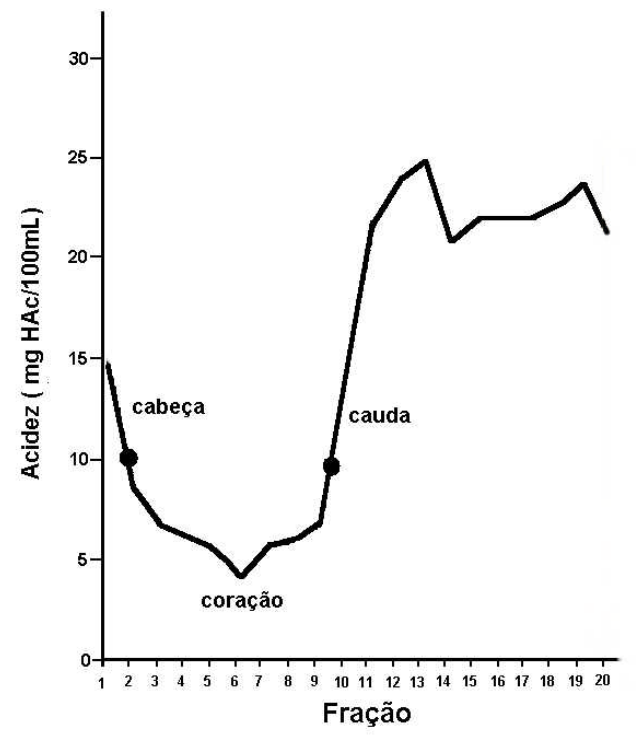




\section{FIGURA 2 - VARIAÇÃO DA CONCENTRAÇÃO DE COBRE NAS FRAÇÕES DO DESTILADO}

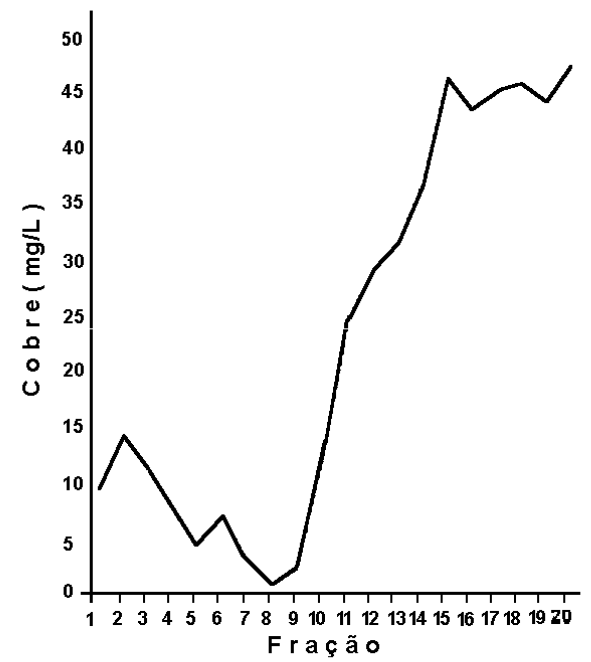

Pelo estudo de correlações entre os teores de analitos, encontrados nas frações seqüenciais de destilado (Tabela 1), verificou-se que os valores dos coeficientes de Pearson, calculados para as correlações entre acidez e grau alcoólico e entre grau alcoólico e teor de cobre foram: - 0,94106 e 0,96434 , respectivamente. As magnitudes dos coeficientes indicam forte correlação entre as variáveis e o sinal negativo indica que estas correlações são inversas. $O$ coeficiente calculado para a correlação entre acidez e teor de cobre foi 0,89341 e, neste caso, positivo o que indica forte correlação direta. A rejeição da hipótese de que a correlação verdadeira é zero ocorre com probabilidade de erro de $0,01 \%$.

Segundo NYKÄNEN \& NYKÄNEN (15) os ácidos orgânicos voláteis, indubitavelmente, contribuem para o flavor das bebidas destiladas devido especialmente ao seu flavor característico, pois são capazes de aumentar a acidez da bebida em pouca extensão. $O$ ácido acético é o predominante, sendo que sua concentração varia amplamente em diferentes bebidas destiladas, porém na maioria dos casos corresponde a percentuais entre 60 e $95 \%$ da acidez total.

BOZA \& HORII (3) correlacionando a composição química e a qualidade sensorial da aguardente verificaram um contraste entre acidez e a qualidade sensorial da aguardente. Assim, recomendaram o "corte" na destilação com produto de alto grau alcoólico para reduzir a acidez e obter 
produto de melhor qualidade sensorial. Conforme pode ser observado na Tabela 1, o corte da destilação com destilado de maior teor alcoólico, ou seja, não esgotando todo álcool presente no vinho reduz, substancialmente, o teor de cobre no produto.

\title{
4 CONCLUSÃO
}

Os resultados obtidos neste trabalho permitem concluir que:

- os teores de cobre durante a destilação correlacionam-se com os teores de acidez encontrados no destilado, sendo elevados principalmente na fração cauda (final) da destilação;

- o grau de remoção da fração cauda influi no teor de cobre do destilado, embora aumente a manipulação na operação de destilação em processo intermitente;

- separando-se a fração cauda a qualidade da aguardente será melhorada pela redução dos níveis de cobre.

\begin{abstract}
The use of copper in the manufacture of stills and auxiliary piping for the sugarcane based distilled beverages industries is a need for the improvement of the sensorial quality of the beverage. The aim of the present work was to correlate the copper content in sugarcane based distilled beverages with alcoholic content and acidity in the distillate. It was verified that the copper content during the distillation process followed the acidity content of the distillate, finding both at higher concentrations in the tail fraction. The distillation was stopped when the product had higher alcoholic grade, then the acidity and copper content were reduced in the distilled beverage.
\end{abstract}

\section{REFERÊNCIAS BIBLIOGRÁFICAS}

1 AMERINE, M.A., BERG, H.W., CRUESS, W.V. Brandy production. In: AMERINE, M. A (ed.). The technology of wine making. 3.ed. Westport : AVI, 1972. Cap. 17, p. 600-644.

2 BEZERRA, C.W.B. Caracterização química da aguardente de cana-de-açúcar: determinação de álcoois, esteres e dos íons $\mathrm{Li}^{+}$, $\mathrm{Ca}^{2+}, \mathrm{Mg}^{2+}, \mathrm{Cu}^{2+}$ e Hg${ }^{2+}$. São Carlos, 1995. 53 p. Dissertação (Mestrado em Química Analítica), Instituto de Química de São Carlos, Universidade de São Paulo. 
3 BOZA, Y.E.A.G., HORII, J. Influência da destilação sobre a composição e a qualidade sensorial da aguardente de cana-deaçúcar. Ciência e Tecnologia de Alimentos, v. 18, n. 4, p. 391396, 1998.

4 BRASIL. Ministério da Agricultura. Decreto $n^{0} 2.314$ de 4 de setembro de 1997. Regulamenta a Lei n. 8.918 de 14 de julho de 1994, que dispõe sobre a padronização, a classificação, o registro, a inspeção, a produção e a fiscalização de bebidas. Diário Oficial [da República Federativa do Brasil], Brasília, 5 de setembro de 1997. p. 19549, Seção I.

5 DAHER, A.L.K, FREITAS, R.J.S. Determinação de cobre em bebidas. Arquivos de Biologia e Tecnologia, v. 23, n. 1, p. 1-9, 1980.

6 FARIA, J.B. A influência do cobre na qualidade das aguardentes de cana (Saccharum officinarum, L.). São Paulo, 1989. 88 p. Tese (Doutorado em Ciências de Alimentos), Faculdade de Ciências Farmacêuticas, Universidade de São Paulo.

7 FURTADO, S.M.B. Avaliação sensorial descritiva de aguardente de cana (Sacharum officinarum, L.): influência da composição em suas características sensoriais e correlação entre as medidas sensoriais e físico-químicas. Campinas, 1995. 99 p. Tese (Doutorado em Tecnologia de Alimentos), Faculdade de Engenharia de Alimentos, Universidade de Campinas.

8 INSTITUTO ADOLFO LUTZ. Normas Analíticas do Instituto Adolfo Lutz. 3.ed. São Paulo, 1985. 533 p.

9 LÉAUTÉ, R. Distillation in alambic. American Journal of Enology and Viticulture, v. 41, n. 1, p. 90-103, 1990.

10 LIMA NETO, B.S., FRANCO, D.W. A aguardente e controle químico de sua qualidade. Engarrafador Moderno, v. 4, n. 33, p. 5-8, 1994.

11 LIMA, U.A. Estudos dos principais fatores que afetam os componentes do coeficiente não álcool das aguardentes de cana. Piracicaba, 1964. 141 p. (Cátedra em Tecnologia do Açúcar e do Álcool), Escola Superior de Agricultura "Luiz de Queiroz", Universidade de São Paulo.

12 MAIA, A.B. Componentes secundários da aguardente. STAB, v. 12, n. 6, p. 29-34, 1999. 
13 MOUTOUNET, M., ESCUDIER, J.L., JOURET, C. Production of spirits by pervaporation: comparison with still distillation.

Lebensmittel Wissenschaft und Technologie, v. 25, p. 71-73, 1992.

14 NOVAES, F.V., OLIVEIRA, E.R., STUPIELLO, J.T. et al. Curso de extensão em tecnologia de aguardente de cana: apontamentos. Piracicaba : ESALQ, 1974. 104 p.

15 NYKÄNEN, L., NYKÄNEN, I. Distilled beverages. In: MAARSE, H., (ed). Volatile compounds in foods and beverages. New York : Marcel Dekker, 1991. Cap. 15.

16 OSSA, E.M., SERRANO, M.A.G. Salt effect of the composition of alcohols obtained from wine by extractive distillation. American Journal of Enology and Viticulture, v. 42, n. 3, p. 252-4, 1991.

17 PEDUTI, F. Controle quantitativo de cobre em aguardentes. Revista do Instituto Adolfo Lutz, v. 3, n. 1, p. 216-223, 1943.

18 RECOMMENDED dietary alowances. 10.ed. Washington : National Academic Press, 1989. Cap.10, p. 195-246.

19 RODELLA, A.A. Determinação espectrofotométrica automatizada de cobre e zinco em amostras de interesse agroindustrial. Campinas, 1993. 132 p. Tese (Doutorado em Química Analítica) Instituto de Química, Universidade de Campinas.

20 SAS INSTITUTE. Statistics Analyses Systems (SAS): Versão 6-09. 4.ed. Cary. NC, 1989. 2 v. (Compact Disc).

21 SERPE, E.R., FREITAS, R.J.S. Avaliação do cobre e zinco em alimentos de consumo diário. Boletim do Centro de Pesquisa e Processamento de Alimentos, v. 9, n. 2, p. 141-148, 1991.

22 SINGH, A., KUHAD, D.C., SAHAI, V., GHOSH, P. Evaluation of biomass. Advances in Biochemical Engineering Biotechnology, v. 51, p. 47-70, 1994.

23 TANNER, N. Production of satisfactory distillates. Schweizerische Zeitschrift für Obstund Wienbau, v. 105, p. 319-28, 1969. Apud Food Science and Technology Abstratcts, v. 2, n. 2, p. 199, 1970.

24 WAINWRIGHT, T. Production of $\mathrm{H}_{2} \mathrm{~S}$ by yeasts: role of nutrients. Journal of Applied Bacteriology, v. 34, n. 1, p. 161-71, 1971. 